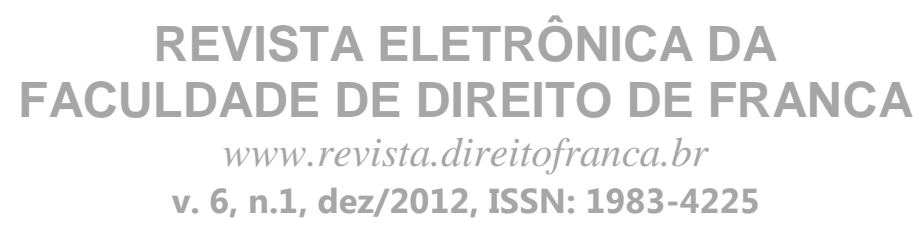

\title{
PERSPECTIVA JURÍDICO-CULTURAL DOS DIREITOS HUMANOS
}

\author{
Anne Caroline Primo Ávila \\ http://buscatextual.cnpq.br/buscatextual/visualizacv.do?id=K4479795Z1
}

\begin{abstract}
Resumo: Os direitos humanos, a partir do seu aparecimento na sociedade como fator de justiça e garantia de direitos essenciais, sofreu grandes transformações e sua aceitação passou a ser cada dia mais importante. Ocorre que em se tratando de um planeta com as mais diversas formas de cultura e costumes, esses direitos passaram a ser interpretados de maneira diversa em cada nação. Assim, essa questão é uma das mais complexas, tendo em vista a existência de direitos considerados universais frente a Cultura e a Constituição de cada sociedade.
\end{abstract}

Palavras-chave: Constituição e Direitos Humanos, Cultura e Direitos Humanos.

\section{Legal and Cultural Perspective of Human Rights}

Abstract: Human rights, from its emergence in society as a factor of justice and basic rights guarantee, has undergone major developments and their acceptance has become increasingly important. What happens is that considering a planet with the most diverse forms of culture and traditions, these rights have been interpreted differently in each nation. And considering the law, the issue becomes even more complex, since the law can be approached by two systems: Civil Law and Common Law depending mainly, on the Constitution which is the key of the conflict and of the gaps found for the non-fulfillment of such important rights.

Key-words: Constitution and Human Rights, Culture and Human Rights

\section{INTRODUÇÃO}

Quando se fala em Direitos Humanos, temos a ideia de abstração, algo que se encontra amplamente distante de aplicação prática e efetiva.

Para alguns países, o fato das Nações Unidas recomendarem o seguimento de condutas definidas na Declaração Universal de Direitos Humanos como direitos humanos, nada mais é do que um incômodo, uma afronta aos costumes e ao ordenamento jurídico nacional.

No entanto, ao analisarmos minunciosamente a questão, perceberemos que o presente tema é muito mais complexo do que aparenta. Assim, para que se cumpra a Declaração Universal de Direitos do Homem e outros tratados internacionais sobre Direitos Humanos não depende pura e simplesmente da participação dos países nas Nações Unidas ou em tais acordos. Precedente aos acordos de Direitos Humanos existe uma Constituição de 


\title{
REVISTA ELETRÔNICA DA FACULDADE DE DIREITO DE FRANCA \\ www.revista.direitofranca.br \\ v. 6, n.1, dez/2012, ISSN: 1983-4225
}

caráter primordial para a organização de uma Nação, e junto dela caminha a cultura de seu povo - que também é uma fonte de direito.

São inúmeros esses direitos, e inúmeras também são as formas com que são desrespeitados. Algumas situações em que há o desrespeito aos direitos humanos causam maior impacto social, ou seja, apelam o clamor público com mais facilidade. No livro Gostaríamos de informá-lo que amanhã seremos mortos com nossas famílias ${ }^{1}$, de Philip Gourevitch em que relata o pós guerra da Ruanda, temos exemplos que nos levam à perplexidade devido à afronta aos direitos humanos, um deles a seguir:

\begin{abstract}
Atravessamos a primeira sala (...). Estavam todas cheias de corpos, e mais corpos estavam espalhados no capim, havia crânios esparsos no capim (...). De pé do lado de fora, escutei um ruído de trituração. $\mathrm{O}$ velho coronel canadense tropeçou à minha frente, e vi que, sem que ele notasse, seu pé pisara sobre um crânio, quebrando-o. Pela primeira vez em Nyarubuye, meus sentimentos entraram em foco, e o que senti foi uma pequena, mas feroz raiva daquele homem. Então ouvi outro ruído, e senti uma vibração sob o pé. Eu havia pisado em um, também. ${ }^{2}$
\end{abstract}

Sob o impacto da nossa indignação sobre tal trecho e o contexto da guerra no país, como cidadãos e sob a ótica da nossa cultura nos revoltaríamos em primeiro plano com a autoridade competente do país que comandou um genocídio por pura e simples questão racial. Em seguida, colocaríamos em dúvida o papel da ONU (Organização das Nações Unidas), partindo do pressuposto de que a mesma deveria ter impedido a dizimação de mais de 6 milhões de pessoas.

Analisando tecnicamente, observaremos que nada é tão simples. As intervenções internacionais e a aplicabilidade dos direitos humanos dependem de diversos fatores. Não se pode ferir a soberania de um país, obrigando seu povo a acatar normas determinadas por uma organização internacional sem considerar a sua cultura. Em contrapartida, não se pode ser conivente com nações que massacram seu povo.

Assim, a tal problemática resume-se em como os direitos humanos podem ser respeitados sem ferir a Constituição de um país e sua cultura? Nesse contexto, desenvolverse-á nossa pesquisa.

\section{UMA ABORDAGEM DOS DIREITOS HUMANOS}

\footnotetext{
1 GOUREVITCH, Philip. Gostaríamos de Informá-lo que amanhã seremos mortos com nossas famílias. Tradução José Geraldo Couto. 1 ed. São Paulo: Companhia de Bolso - 2006.

2 Ibid., p. 20.
} 


\section{REVISTA ELETRÔNICA DA FACULDADE DE DIREITO DE FRANCA \\ $w w w . r e v i s t a . d i r e i t o f r a n c a . b r$ \\ v. 6, n.1, dez/2012, ISSN: 1983-4225}

\subsection{Conceito, contexto histórico e importância}

Os Direitos humanos receberam ao longo dos anos várias definições e sua existência foi ganhando força com a elaboração de documentos oficiais internacionais, no entanto, essa não é a garantia de que esses direitos venham ser respeitados em todos os países e que sua existência seja fato nos mesmos.

Direitos Humanos são aqueles direitos definidos por muitos autores como "direitos inerentes à vida, à segurança individual, aos bens que preservam a humanidade"3. Estes direitos possuem existência real e aplicabilidade a partir do seu reconhecimento pelo poder legislativo do país.

Partindo da introdução de Fábio Konder Comparato sobre a situação do homem no mundo temos a afirmação: “...É reconhecimento universal de que (...) - nenhum indivíduo, gênero, etnia, classe social, grupo religioso ou nação - pode afirmar-se superior aos demais." Tomando por base tal afirmação, fica clara a complexidade do ser humano que se coloca ao mesmo tempo como diferente dos demais da sua espécie e ao mesmo tempo igual.

A distinção abordada consiste na diferença cultural que cada sociedade construiu através das circunstâncias históricas e da adaptação à evolução. Questão que estudaremos mais a frente.

A igualdade é baseada na predeterminação de que todos os homens devem ter as mesmas oportunidades. Essa igualdade, do ponto de vista jurídico, consiste em portar os mesmos direitos e os mesmos deveres, ou seja, suas diferenças não podem determinar uma relação de superioridade e inferioridade.

Nessa mesma linha de pensamento, podemos citar o artigo I, da Declaração Universal dos Direitos do Homem: "Todos os homens nascem livres e iguais em dignidade e direitos. São dotados de razão e consciência e devem agir em relação uns aos outros com espírito de fraternidade."5

Aproveitando o liame aberto pela citação desse e ao mesmo tempo contextualizando historicamente os direitos humanos, veremos que antes da publicação da Declaração

\footnotetext{
${ }^{3}$ DORNELLES, João Ricardo W. O que são direitos humanos. 1. ed. São Paulo: Brasiliense, 1989. p. 09.

${ }^{4}$ COMPARATO, Fábio Konder. A afirmação histórica dos direitos humanos. 3. ed. São Paulo: Saraiva, 2004. p. 01.

5 ORGANIZAÇÃO DAS NAÇÕES UNIDAS. Declaração Universal dos Direitos Humanos (1948). Departamento de Informação Pública, 2000, p.06.
} 


\section{REVISTA ELETRÔNICA DA \\ FACULDADE DE DIREITO DE FRANCA \\ www.revista.direitofranca.br \\ v. 6, n.1, dez/2012, ISSN: 1983-4225}

Universal de Direitos Humanos, muitos fatos antecedentes deram início às discussões do tema.

Em 1789, ocorreu o início da Revolução Francesa, em que foi aprovada a Declaração dos Direitos do Homem e do Cidadão, que garantia igualdade jurídica e propriedade privada na França. A Independência dos Estados Unidos da América em 1776, que foi seguida da Declaração de Independência - que garantia os direitos fundamentais do cidadão, tais como liberdade e igualdade - sendo à época um grande marco político, jurídico e social.

Em 1948, a Assembléia Geral das Nações Unidas aprovou o projeto da Declaração Universal de Direitos Humanos, elaborada pela Comissão de Direitos Humanos das Nações Unidas. O referido documento foi redigido tendo por base os acontecimentos da época: $2^{\circ}$ Guerra Mundial. Mesmo tendo sido aprovada por unanimidade, alguns países se abstiveram da votação: países comunistas (União Soviética, Ucrânia e Rússia Branca, Tchecoslováquia, Polônia e Iuguslávia), Arábia Saudita e África do Sul ${ }^{6}$.

\subsection{Aplicabilidade}

A Declaração Universal de Direitos do Homem vem como uma recomendação aos membros da Assembléia Geral das Nações Unidas. O documento não tem força vinculante. Porém, a vigência dos direitos humanos independe de sua declaração em constituições, leis e tratados internacionais, porque se está diante de exigências de respeito à dignidade humana, exercidas contra todos os poderes estabelecidos, oficiais ou não.

Em primeiro lugar devemos observar a sutil diferença entre Direitos Humanos e Direitos Fundamentais. Falar de um não é necessariamente estar falando do outro. Os direitos humanos podem ser direitos fundamentais, mas os direitos fundamentais sempre são direitos humanos. Pois bem, o primeiro trata de exigências de respeito à dignidade humana, como supracitado; já o segundo são os direitos humanos considerados pelo Estado como regras constitucionais escritas (formalmente).

Ao entrar na questão do Direito Internacional, mais propriamente dos tratados, observaremos que eles se constroem de costumes e princípios gerais de direito, portanto, os acordos se firmam com base no que se possui de mais importante em um país.

\footnotetext{
${ }^{6}$ COMPARATO, Fábio Konder. A afirmação histórica dos direitos humanos. 3. ed. São Paulo: Saraiva, 2004. p. 223.
} 


\section{REVISTA ELETRÔNICA DA \\ FACULDADE DE DIREITO DE FRANCA \\ www.revista.direitofranca.br \\ v. 6, n.1, dez/2012, ISSN: 1983-4225}

Então, a aplicabilidade dos Direitos Humanos dependerá principalmente da situação normativa e da cultura de um país.

\section{CONSTITUIÇÃO}

\subsection{Conceito}

Partindo da posição hierárquica das normas jurídicas observaremos que no topo da pirâmide do direito encontra-se a Constituição (análise no sentido formal). Ao passarmos por diversos autores perceberemos que inúmeras são as maneiras de se definir o que é uma Constituição. Além da posição hierárquica superior, seu conteúdo (sentido material) vem delimitar os poderes do Estado, definir a organização do mesmo e garantir os direitos fundamentais. Seja no âmbito político, jurídico ou sociológico, a Constituição poder ser definida como:

a organização sistemática dos elementos constitutivos do Estado, através da qual se definem a forma e a estrutura deste, o sistema de governo, a divisão e o funcionamento dos poderes, o modelo econômico e os direitos, deveres e garantias fundamentais, sendo que qualquer outra matéria que for agregada a ela será considerada formalmente constitucional. ${ }^{7}$

Nesse contexto, cabe mencionar a Teoria da Constituição, que segundo Carl Schmitt:

é a teoria daquilo que forma um Estado, isto é, da unidade política de um povo. Com essa assertiva já é possível perceber que há diferença entre a ideia material de Constituição e o conceito formal de constituição, o qual a coloca, neste último caso, como um mero sistema de normas, sem obrigatoriedade de consonância com a realidade do povo e sem obrigatoriedade de ser ideal. ${ }^{8}$

Hans Kelsen trata do tema, conforme cita Eduardo Almeida Pellerin da Silva:

Essa norma suprema é a norma fundamental, que segundo Kelsen, existe em todo ordenamento e é ela que dá a unidade, unifica as outras normas, formando um todo chamado de ordenamento jurídico. Sem ela, não se poderia falar em ordenamento, e as normas formariam um composto amontoado e disperso. Ou seja, a quantidade e variedade de fontes do direito em um ordenamento complexo, constituem um ordenamento unido pelo fato de que todas as fontes remetem, em última instância, a uma única norma. ${ }^{9}$

\footnotetext{
${ }^{7}$ ARAÚJO, Luiz Alberto David; NUNES JUNIOR, Vidal Serrano. Curso de Direito Constitucional. 9 ed. São Paulo: Saraiva, 2005. p.03.

${ }^{8}$ BOSTELMANN, Elisa Mayara; KAMPMANN, Fábio Roberto; OLIVEIRA NETO, Orleans Antunes de; PERAZZOLI, Fernando David; VIEIRA, Cainã Domit. A Teoria da Constituição na obra de Carl Schmitt. Disponível em: <http://www.abdconst.com.br/revista3/portouniao.pdf>. Acesso em: 14 dez. 2012.

9 SILVA, Eduardo Almeida Pellerin da. A unidade do ordenamento jurídico segundo Bobbio. Disponível em: 〈http://jus.com.br/revista/texto/22291>. Acesso em: 14 dez. 2012.
} 


\section{REVISTA ELETRÔNICA DA FACULDADE DE DIREITO DE FRANCA \\ www.revista.direitofranca.br \\ v. 6, n.1, dez/2012, ISSN: 1983-4225}

Assim, tomando por base tais doutrinadores, podemos afirmar que a Constituição é a base do ordenamento jurídico, o que faz com que o mesmo seja harmônico e organizado, transcrevendo em um documento a realidade fática de uma sociedade.

\subsection{Força normativa}

Ferdinand Lassalle costumava dizer que o documento que consiste na Constituição Jurídica, nada mais é do que Ein Stück Papier (um pedaço de papel) ${ }^{10}$. No entender do alemão, as questões constitucionais são políticas e não jurídicas. Encontram-se expressos na Constituição relações de poder dominantes no país: Poder Militar, Poder Social, Poder Econômico e Poder Intelectual - que se colocam como fatores reais do poder que formariam a Constituição Real (de caráter político).

Em contrapartida, o também alemão e professor Konrad Hesse defende uma tese contrária a de Lassalle. Hesse coloca como força determinante do Direito Constitucional a reciprocidade entre a Constituição Jurídica e a realidade político-social ${ }^{11}$. Importante também, no seu ponto de vista, é que há a necessidade de considerarmos os limites e as possibilidades da atuação da Constituição Jurídica e investigar os pressupostos de eficácia da mesma. Apesar da concepção diversa entre a força condicionante da realidade e a normatividade da Constituição, não podemos separá-las. A construção de uma Constituição poderia ser comparada a uma árvore, tendo por raízes a normatividade - que é a força do Direito Constitucional; e tendo por adubo, luz e água, a força condicionante da realidade - que é o que faz o Direito Constitucional crescer forte e atingir seu propósito: regular as ações de um Estado, delimitar suas competências e garantir os Direitos Fundamentais; que para a árvore seriam os frutos.

\footnotetext{
${ }^{10}$ LASSALE, Ferdinand, apud HESSE, Konrad. A força normativa da Constituição (Die normative Kraft der verfassung). Tradução de Gilmar Ferreira Mendes. Porto Alegre: Sérgio Antônio Fabris Editor, 1991. p. 09.

11 "A questão aqui apresentada sobre a força normativa não constitui indagação da teoria das fontes jurídicas. Não é decisivo, assim, definir se princípios do direito suprapositivo podem integrar a 'Constituição Jurídica'. A problemática subsiste mesmo em caso de uma resposta afirmativa”. HESSE, Konrad. A força normativa da Constituição (Die normative Kraft der verfassung). Tradução de Gilmar Ferreira Mendes. Porto Alegre: Sérgio Antônio Fabris Editor, 1991. p. 13.
} 


\section{REVISTA ELETRÔNICA DA \\ FACULDADE DE DIREITO DE FRANCA \\ www.revista.direitofranca.br \\ v. 6, n.1, dez/2012, ISSN: 1983-4225}

Assim, diz Hesse: "somente a Constituição que se vincula a uma situação histórica concreta e suas condicionantes, dotada de uma ordenação jurídica orientada pelos parâmetros da razão, pode, efetivamente, desenvolver-se" ${ }^{\prime 12}$.

Tomando por base Hesse e Lassale, podemos concluir que uma Constituição Jurídica deve existir não só pelos fatores políticos e sociais e nem só pela força jurídica. Uma verdadeira Constituição, que possua força normativa deve depender de vários fatores que a condicione. Uma Constituição só será legítima e só terá força normativa se em seu corpo, contextualizar a situação histórica, os fatos sociais, a ordenação jurídica, a cultura e costumes de seu povo e, sobretudo, com normas constitucionais rígidas (mais estáveis que as demais normas do país).

\section{CULTURA}

\subsection{Conceito}

Podemos iniciar a discussão desse tema com o conceito dado pelo livro Antropologia: uma introdução ${ }^{13}$ : “As sociedades são formadas de seres humanos que adotam uma forma de viver normativa, isto é, tornam-se elementos de outras culturas, em geral adaptadas à ambiência local”.

Nesse sentido, pode-se afirmar que cultura é tudo aquilo que um povo produz durante sua existência e por sua repetição se torna algo concreto e aplicável às gerações futuras.

Ruth Benedict afirmou que "a sociedade e o indivíduo não são antagônicos, mas interdependentes" 14 , ou seja, a cultura é a base das relações do homem em sociedade.

Uma sociedade não se faz de um único indivíduo, o mesmo ocorre com a cultura. Não há possibilidade da formação de uma cultura sem que os indivíduos possam conviver em grupos, produzindo hábitos e costumes que possam ser transferidos através das gerações.

Cultura é um termo que abrange inúmeras definições e tentar restringir seu conceito seria um tanto quanto perigoso. Mas de forma geral, ressaltando as principais características já

\footnotetext{
${ }^{12}$ HESSE, Konrad. A força normativa da Constituição (Die normative Kraft der verfassung) . Tradução de Gilmar Ferreira Mendes. Porto Alegre: Sérgio Antônio Fabris Editor, 1991. p. 16.

${ }^{13}$ MARCONI, Marina de Andrade; PRESOTTO, Zélia Maria Neves. Antropologia: uma introdução. 6 ed. São Paulo: Atlas, 2007.

14 Ibid.
} 


\section{REVISTA ELETRÔNICA DA \\ FACULDADE DE DIREITO DE FRANCA \\ $w w w . r e v i s t a . d i r e i t o f r a n c a . b r$ \\ v. 6, n.1, dez/2012, ISSN: 1983-4225}

citadas, cultura é tudo aquilo que um povo produz e repassa através de repetições, tornando os hábitos de certa forma permanentes em seu grupo social.

\subsection{Importância histórica}

As culturas estão sempre em constante movimento, apesar de algumas parecerem estáticas, sofrem mudanças, mesmo que minuciosas. Essas mudanças se dão com o passar dos anos e o contato com outras sociedades, e em seguida dão origem a novos hábitos, costumes e consequentemente novas regras sociais e legais.

Cultura é algo que não se produz sozinho, como diz Luiz Gonzaga de Mello: "a cultura é um modo coletivo de provar a sobrevivência de todos e de cada um dos membros da população". ${ }^{15}$ Ela é produto das relações inter-pessoais existentes no grupo.

A cultura não só é importante para a história com é constituída da própria história. $\mathrm{O}$ homem com o descobrimento do fogo desencadeou muitas outras descobertas, tradições foram sendo formadas e marcadas na história como fatos sociais importantes para se analisar o ponto em que se encontram as sociedades atuais e as mutações que as mesmas sofreram.

Um simples objeto natural - uma pedra, digamos - se utilizado pelo homem, mesmo sem modificação de sua estrutura - usada como peso de papéis, suponhamos - já se tornou cultura, por passar a funcionar na vida humana, no mundo do homem, onde se lhe atribui um posto e um sentido. ${ }^{16}$

Assim, a cultura é uma das bases mais importantes no convívio social dos homens.

\subsection{Universalismo versus relativismo cultural}

Acerca da aplicação dos Direitos Humanos no mundo, foram desenvolvidas duas teorias: universalismo e relativismo.

O universalismo defende que os direitos humanos decorrem do princípio da dignidade da pessoa humana, existindo um mínimo ético irredutível ${ }^{17}$, o qual não pode ser descumprido, independente de qualquer justificativa. Nessa corrente, alguns direitos devem ser respeitados em todo o mundo, independente do restante do ordenamento jurídico, ou sua cultura.

\footnotetext{
${ }^{15}$ MELLO, Luiz Gonzaga de. Antropologia Cultural - Iniciação, Teoria e Temas. 14 ed. Petrópolis: Vozes 2008. p. 80.

${ }^{16}$ NETO, A. L. Machado. Sociologia Jurídica. 6 ed. São Paulo: Saraiva - 1987. p. 155.

${ }^{17}$ PIOVESAN, Flávia. Direitos humanos e justiça internacional. 3. ed. São Paulo: Saraiva, 2012. p. 47.
} 


\section{REVISTA ELETRÔNICA DA FACULDADE DE DIREITO DE FRANCA \\ www.revista.direitofranca.br \\ v. 6, n.1, dez/2012, ISSN: 1983-4225}

Já o relativismo argumenta que os direitos estão intrinsecamente relacionados ao sistema político, econômico, cultural, social e moral de cada povo, ou seja, os direitos humanos só poderão ser aplicados se em conformidade com a cultura e as normas jurídicas vigentes em cada sociedade.

Entretanto, as duas correntes se contrapõem, uma nega a outra e ambas sofrem críticas dos doutrinadores.

Alguns autores, como Mary Beniticte Dembour afirma que uma teoria não pode ser considerada independente da outra, e ressalta que em cada situação devemos adotar uma posição $^{18}$. Seria essa uma posição intermediária, tendo em vista a possibilidade de aplicação das duas correntes doutrinárias.

O sociólogo português Boaventura de Sousa Santos apresenta uma possibilidade inovadora consistente no diálogo das culturas. Para Boaventura a discussão entre universalismo e relativismo deve ser superada através do diálogo entre as culturas a fim de compor um multiculturalismo emancipatório ${ }^{19}$, ou seja, ele propõe uma alternativa baseada na tolerância e no respeito mútuo entre as culturas.

Tais correntes tentam defender cada qual sua posição sobre como deveriam ser aplicados os direitos humanos em países culturalmente diferentes.

\section{RELAÇÃO DIREITO-CULTURA DOS DIREITOS HUMANOS}

\subsection{Aspectos gerais}

Levando em consideração as informações supramencionadas e o peso individual de cada item estudado: Direitos Humanos, Constituição e Cultura; observaremos que em cada região um fator será mais preponderante, mas que em todas a Constituição é aquela que possui maior peso.

A Constituição deve ser cumprida sempre, mas em alguns casos a mesma traz vícios em relação à maneira como trata seu povo, ferindo sua dignidade e outros direitos essenciais para sua vida, nesses casos, acredita-se que alguns pontos devem ser reconsiderados.

O poder constituinte ao definir as regras de organização política do Estado e os direitos fundamentais do indivíduo, deve levar em conta os costumes, respeitando sempre a

\footnotetext{
18 SOUSA, Ariana Meireles. Universalismo versus Relativismo. Disponível em: <http://sociuslogia.blogspot.com.br/2009/01/universalismo-versus-relativismo_27.html> Acesso em: 25 jan. 2012.

${ }^{19}$ PIOVESAN, Flávia. Direitos humanos e justiça internacional. 3. ed. São Paulo: Saraiva, 2012. p. 48.
} 


\title{
REVISTA ELETRÔNICA DA FACULDADE DE DIREITO DE FRANCA \\ $w w w . r e v i s t a . d i r e i t o f r a n c a . b r$ \\ v. 6, n.1, dez/2012, ISSN: 1983-4225
}

cultura de cada povo. Uma cultura leva muito tempo para se formar, e apesar de estar em constante mutação é a base da convivência dos homens em sociedade.

Partindo desse pressuposto, nenhuma constituição deve ferir alguns direitos que são primordiais para a existência digna de qualquer ser humano: vida, respeito às diferenças e condições para que ele encontre melhores maneiras para se viver.

Juridicamente, os direitos humanos só poderão ser cobrados ao fazerem parte da Constituição da Nação, tanto no aspecto material quanto no formal. Entretanto, isso não pode ser obtido por meio de imposição, mas pela conscientização e pela conquista da confiança entre as Nações.

\subsection{A recepção dos Tratados Internacionais de Direitos Humanos pela Constituição Federal Brasileira}

Em 2004, houve uma Reforma Judiciária - Emenda Constitucional 45/2004 tratando dos direitos humanos, a mesma incluiu o $\S 3^{\circ}$ ao artigo $5^{\circ}$ da Constituição, que atribuiu aos tratados internacionais equivalência de Emendas Constitucionais. Mas eis que já havia o $\S 2^{\circ}$ do mesmo artigo e ambos que abriram uma complexa discussão em torno do assunto.

Observe o artigo e em seguida a diferença entre ambos, é sublime, mas perceptível: Art. $5^{\circ}, \S 2^{\circ}, C F$ : “Os direitos e garantias expressos nesta Constituição não excluem outros decorrentes do regime e dos princípios por ela adotados, ou dos tratados internacionais em que a República Federativa do Brasil seja parte”.

Por este parágrafo, fica claro que o direito brasileiro sempre admitiu o ingresso dos tratados internacionais como normas constitucionais, porém só lhes atribuía o status de norma constitucional.

\begin{abstract}
Art. $5^{\circ}, \S 3^{\circ}, C F-$ Os tratados e convenções internacionais sobre direitos humanos que forem aprovados, em cada Casa do Congresso Nacional, bem dois turnos, por três quintos dos votos dos respectivos membros, serão equivalentes às emendas constitucionais. ${ }^{20}$
\end{abstract}

Nesse caso, os tratados devem ser aprovados por maioria qualificada após a entrada em vigor, para equivalerem hierarquicamente a lei Federal. Sua equivalência é a uma emenda constitucional, que se traduz em norma formalmente constitucional (integrariam o texto).

\footnotetext{
${ }^{20}$ BRASIL. Constituição da República Federativa do Brasil (1988). Vade Mecum Compacto. 5. ed. São Paulo: Saraiva, 2011. p.13.
} 


\section{REVISTA ELETRÔNICA DA FACULDADE DE DIREITO DE FRANCA \\ $w w w . r e v i s t a . d i r e i t o f r a n c a . b r$ \\ v. 6, n.1, dez/2012, ISSN: 1983-4225}

Então, a inclusão do $\S 3^{\circ}$, é prova de que o Brasil deve cumprir acordos internacionais e de direitos humanos, sob pena de ser responsabilizado em caso de denúncia de descumprimento.

Segundo o constitucionalista Valério Mazzuoli, os efeitos provocados pela emenda 45/2004 foram: “1) passarão a reformar a constituição; 2) não poderão ser denunciados, nem mesmo com projeto de denúncia elaborado pelo Congresso Nacional, podendo o presidente ser responsabilizado em caso de descumprimento" ${ }^{, 21}$.

Sintetizando, o efetivo cumprimento dos tratados internacionais de Direitos Humanos no Brasil se dá através da inclusão de tais direitos na Constituição. Assim, os direitos humanos só serão de caráter obrigatório segundo a lei, a partir do momento em que o Brasil aprovar os tratados e aplicar a eles o artigo $5^{\circ}, \S 3^{\circ}$ da Constituição Federal.

\section{CONSIDERAÇÕES FINAIS}

Conseguinte os fatores e condições relatados na presente pesquisa, constata-se que as leis devem formar um conjunto harmônico com aplicação direta à sua sociedade.

Assim, afirma-se que não basta que as Nações Unidas estejam dispostas a alterar Constituições e sobrepor seus preceitos a um povo que nasceu obedecendo e seguindo determinada cultura.

Verdade é que não se pode tolerar abusos de governantes e ações radicais. No entanto, a questão não é tão simples assim.

É inaceitável aplicar impositivamente regras de conduta incompatíveis com os costumes, há de se ter como supracitado, uma conexão, uma harmonia entre a Constituição, a cultura e os Direitos Humanos.

Uma questão de tamanha complexidade, só poderá começar a ser resolvida através de bons argumentos e de conscientização, sem tentar impor nada a nenhum povo. A partir do momento em que as Nações se predispuserem a realmente debater Direitos Humanos da perspectiva do respeito às culturas e da dignidade da pessoa humana, estaremos com toda a certeza, diante da base para a aceitação e verdadeira aplicação de direitos de tamanha importância.

21 MAZZUOLI, Valério de Oliveira. Reforma do judiciário e os tratados de Direitos humanos. Disponível em: <http://www.revistajuridicaunicoc.com.br/midia/arquivos/ArquivoID_63.pdf>. Acesso em: 03 fev. 2010. 


\section{REVISTA ELETRÔNICA DA FACULDADE DE DIREITO DE FRANCA \\ www.revista.direitofranca.br \\ v. 6, n.1, dez/2012, ISSN: 1983-4225}

\section{REFERÊNCIAS BIBLIOGRÁFICAS}

ARAÚJO, Luiz Alberto David; NUNES JUNIOR, Vidal Serrano. Curso de Direito Constitucional. 9 ed. São Paulo: Saraiva, 2005.

COMPARATO, Fábio Konder. A afirmação histórica dos direitos humanos. 3. ed. São Paulo: Saraiva, 2004.

DALLARI, Dalmo de Abreu. O que são direitos da pessoa. 10 ed. São Paulo: Brasiliense, 1994.

DORNELLES, João Ricardo W. O que são direitos humanos. 1. ed. São Paulo: Brasiliense, 1989.

GOUREVITCH, Philip. Gostaríamos de Informá-lo que amanhã seremos mortos com nossas famílias. Tradução José Geraldo Couto. 1 ed. São Paulo: Companhia de Bolso, 2006.

HESSE, Konrad. A força normativa da Constituição (Die normative Kraft der verfassung). Tradução de Gilmar Ferreira Mendes. Porto Alegre: Sérgio Antônio Fabris Editor, 1991.

MARCONI, Marina de Andrade; PRESOTTO, Zélia Maria Neves. Antropologia: uma introdução. 6 ed. São Paulo: Atlas, 2007.

MELLO, Luiz Gonzaga de. Antropologia Cultural - Iniciação, Teoria e Temas. 14 ed. Petrópolis: Vozes, 2008.

NETO, A. L. Machado. Sociologia Jurídica. 6 ed. São Paulo: Saraiva, 1987.

PETTA, Nicolina Luiza de; OJEDA, Eduardo Aparício Baez. História: uma abordagem integrada. Vol. Ú. 2 ed. São Paulo: Moderna, 2003.

PIOVESAN, Flávia. Direitos humanos e justiça internacional. 3. ed. São Paulo: Saraiva, 2012.

SANTOS, Robson dos. Artigo: Afinal, o que são Direitos Humanos - Revista: Sociologia ciência e vida. $\mathrm{N}^{\circ} 05$, ano 1. São Paulo: Escala. p 38.

\section{PESQUISAS ELETRÔNICAS}

BOSTELMANN, Elisa Mayara; KAMPMANN, Fábio Roberto; OLIVEIRA NETO, Orleans Antunes de; PERAZZOLI, Fernando David; VIEIRA, Cainã Domit. A Teoria da Constituição na obra de Carl Schmitt. Disponível em: <http://www.abdconst.com.br/revista3/portouniao.pdf>. Acesso em: $14 \mathrm{dez}$. 2012.

MAZZUOLI, Valério de Oliveira. Reforma dojudiciário e os tratados de Direitos humanos. Disponível em: $<$ http://www.revistajuridicaunicoc.com.br/midia/arquivos/ArquivoID_63.pdf. Acesso em: 03 fev. 2010. 


\section{REVISTA ELETRÔNICA DA FACULDADE DE DIREITO DE FRANCA \\ www.revista.direitofranca.br \\ v. 6, n.1, dez/2012, ISSN: 1983-4225}

SILVA, Eduardo Almeida Pellerin da. A unidade do ordenamento jurídico segundo Bobbio. Disponível em: <http://jus.com.br/revista/texto/22291〉. Acesso em: 14 dez. 2012.

SOUSA, Ariana Meireles. Universalismo versus Relativismo. Disponível em: <http://sociuslogia.blogspot.com.br/2009/01/universalismo-versus-relativismo_27.html> Acesso em: 25 jan. 2012.

\section{LEGISLAÇÃO}

ORGANIZAÇÃO DAS NAÇÕES UNIDAS. Declaração Universal dos Direitos Humanos (1948). Departamento de Informação Pública, 2000, p. 06.

BRASIL. Constituição da República Federativa do Brasil (1988). Vade Mecum Compacto. 5. ed. São Paulo: Saraiva, 2011. 